\title{
True Posterior Communicating Artery Aneurysms with High Risk of Rupture despite Very Small Diameter
}

\author{
Dong Gyu Shin, Jaechan Park, ${ }^{1}$ Myungsoo Kim, ${ }^{1}$ Byoung-Joon Kim, ${ }^{1}$ Im Hee Shin ${ }^{2}$ \\ Department of Neurosurgery, School of Medicine, Kyungpook National University, Daegu, Korea \\ Department of Medical Statistics, ${ }^{2}$ School of Medicine, Daegu Catholic University, Daegu, Korea
}

Objective : This retrospective study investigated the clinical and angiographic characteristics of ruptured true posterior communicating artery ( $\mathrm{PCOA}$ ) aneurysms in comparison with junctional PCoA aneurysms presenting with a subarachnoid hemorrhage.

Methods : The medical records and radiological data of 93 consecutive patients who underwent three-dimensional rotational angiography and surgical or endovascular treatment for a ruptured junctional or true PCoA aneurysm over an 8-year period were examined.

Results : The maximum diameter of the ruptured true PCoA aneurysm $(n=13,14.0 \%)$ was significantly smaller than that of the ruptured junctional PCoA aneurysms $(n=80,4.45 \pm 1.44$ vs. $7.68 \pm 3.36 \mathrm{~mm}, p=0.001)$. In particular, the incidence of very small aneurysms $<4 \mathrm{~mm}$ was $46.2 \%$ (six of 13 patients) in the ruptured true PCoA aneurysm group, yet only $2.5 \%$ (two of 80 patients) in the ruptured junctional PCoA aneurysm group. Meanwhile, the diameter of the PCoA was significantly larger in the true PCoA aneurysm group than that in the junctional PCoA aneurysm group $(1.90 \pm 0.57$ vs. $1.15 \pm 0.49 \mathrm{~mm}, p<0.001)$. In addition, the ipsilateral $\mathrm{PCoA} / \mathrm{P} 1$ ratio was significantly larger in the true $\mathrm{PCoA}$ aneurysm group than that in the group of a junctional $\mathrm{PCoA}$ aneurysm (mean $P C o A / P 1$ ratio \pm standard deviation, $2.67 \pm 1.22$ vs. $1.14 \pm 0.88 ; p<0.001)$. No between-group difference was identified for the modified Fisher grade, clinical grade at admission, and 3-month modified Rankin Scale score.

Conclusion : A true PCoA aneurysm was found to be associated with a larger PCoA and ruptured at a smaller diameter than a junctional PCoA aneurysm. In particular, the incidence of a ruptured aneurysm with a very small diameter $<4 \mathrm{~mm}$ was significantly higher among the patients with a true PCoA aneurysm.

Key Words : Internal carotid artery · Intracranial aneurysm · Subarachnoid hemorrhage.

\section{INTRODUCTION}

A typical, junctional posterior communicating artery (PCoA) aneurysm, accounting for about $25 \%$ of all intracranial aneurysms ${ }^{14)}$, originates just distal to the origin of the PCoA from the posterolateral wall of the internal carotid ar- tery (ICA), and hence is classified as an ICA aneurysm. In contrast, a true PCoA aneurysm arises from the PCoA itself. Thus, careful angiographic evaluation at the junctional area of the ICA and PCoA is required to discriminate between a typical, junctional PCoA aneurysm and a true PCoA aneurysm, where the incidence of a true PCoA aneurysm is $>10 \%$ of the

- Received : March 20, 2021 • Revised : June 3, 2021 •Accepted : August 4, 2021

- Address for reprints : Jaechan Park

Department of Neurosurgery, Kyungpook National University Hospital, 130 Dongdeok-ro, Jung-gu, Daegu 41944, Korea

Tel : +82-53-200-5647, Fax : +82-53-423-0504, E-mail : jparkmd@hotmail.com or jparkneurosurgery@gmail.com, ORCID : https://orcid.org/0000-0001-7572-3260

This is an Open Access article distributed under the terms of the Creative Commons Attribution Non-Commercial License (http://creativecommons.org/licenses/by-nc/4.0) which permits unrestricted non-commercial use, distribution, and reproduction in any medium, provided the original work is properly cited. 
incidence of the typical, junctional PCoA aneurysm ${ }^{5,6)}$.

The aneurysm characteristics and rupture risk at the junctional area of the ICA and PCoA can differ according to the exact origin of the aneurysm, leading to different treatment decisions. He et al. ${ }^{6}$ suggested that true PCoA aneurysms can pose a higher risk of rupture than typical, junctional PCoA aneurysms of the same size.

Accordingly, this retrospective study compared the clinical and angiographic characteristics of ruptured true PCoA aneurysms and typical junctional PCoA aneurysms presenting with a subarachnoid hemorrhage. The study results could also be extrapolated for patients with an unruptured true PCoA aneurysm.

\section{MATERIALS AND METHODS}

\section{Patient population}

This retrospective study was reviewed and approved by the Ethics Committee at Kyungpook National University Hospital (IRB No. 2018-06-032). Eligible patients included those who presented with a ruptured PCoA aneurysm including a junctional type and true type, at the authors' institution between January 2012 and December 2019. The treatment decision, surgical versus endovascular, was made primarily based on the findings of preoperative digital subtraction angiography (DSA). Surgical clip placement or endovascular coiling was then performed via an emergency procedure ${ }^{18)}$.

The inclusion criteria for this study were as follows : 1) age $>20$ years, 2) presentation with a subarachnoid hemorrhage, 3) diagnosis of a typical or true PCoA aneurysm based on preoperative DSA, and 4) aneurysm treatment with surgical clipping or endovascular coiling. The exclusion criteria were patients with an unruptured typical or true PCoA aneurysm.

\section{Data collection}

The medical records were reviewed to obtain relevant clinical information, and all the radiological data were obtained using an electronic picture archiving and communication system. The angiographic diagnosis and measurement of the aneurysm and related vessels were determined using the preoperative $3 \mathrm{D}$ rotational DSA in addition to $3 \mathrm{D}$ volume-rendered reconstruction and maximum intensity projection analysis for every patient in this study. The PCoA diameter was measured at the point $10 \mathrm{~mm}$ distal to the PCoA origin.

For those patients with a very small ruptured aneurysm of less than $4 \mathrm{~mm}$, the digital recording of the intraoperative microscope was reviewed to identify any intraoperative rupture during the aneurysm dissection due to the structural fragility of the aneurysm.

\section{Statistical analysis}

The statistical analyses were performed with the aid of commercially available statistics software (IBM SPSS version 19.0; SPSS, Inc., Chicago, IL, USA). To compare the patient-related and aneurysm-related characteristics of the true type and junctional type PCoA aneurysms, a chi-square test was performed for the categorical variables including sex, modified Fisher grade, World Federation of Neurosurgical Societies (WFNS) clinical grade, presentation with oculomotor nerve palsy, treatment modality, and 3-month modified Rankin Scale (mRS) score, while a two sample t-test was performed for the quantitative variables (age, maximum aneurysm diameter, aneurysm neck diameter, aneurysm height, aspect ratio of the aneurysm, diameter of the PCoA, and ipsilateral PCoA/ $\mathrm{P} 1)$. The results were considered significant for probability values less than 0.05 .

\section{RESULTS}

\section{Patients}

During an 8-year period, a total of 93 consecutive patients presenting with a subarachnoid hemorrhage due to a junctional or true PCoA aneurysm rupture were included in this retrospective study, where 80 patients $(86.0 \%)$ had a typical, junctional PCoA aneurysm, while 13 patients (14.0\%) had a true PCoA aneurysm.

In the present series, all the true PCoA aneurysms arose in the proximal part of the PCoA, and the location of the aneurysm neck was within $3 \mathrm{~mm}$ of the PCoA origin.

\section{Comparison of true type and junctional type PCoA aneurysms}

The aneurysm-related and patient-related characteristics of the true and junctional PCoA aneurysms presenting with a subarachnoid hemorrhage are compared in Table 1. Both groups were comparable as regards patient age and sex, where 
the mean age was $57.3 \pm 12.8$ years and 11 patients $(84.6 \%)$ were female in the true PCoA aneurysm group, while the mean age was $62.5 \pm 13.1$ years and 67 patients $(83.8 \%)$ were female in the junctional PCoA aneurysm group.

When the patients presented with a ruptured aneurysm, the maximum diameter of the true PCoA aneurysms was significantly smaller than that of the junctional PCoA aneurysms (mean aneurysm diameter \pm standard deviation [SD], 4.45士
1.44 vs. $7.68 \pm 3.36 \mathrm{~mm} ; p=0.001)$. The diameter of the ruptured true PCoA aneurysms ranged from 2.6 to $6.7 \mathrm{~mm}$, while the diameter of the ruptured junctional PCoA aneurysms ranged from 2.5 to $22.0 \mathrm{~mm}$. Moreover, the distribution of ruptured aneurysms according to aneurysm diameter was as follows and significantly differed according to the aneurysm type $(p<0.001)$ : six patients $(46.2 \%)$ with a diameter $<4 \mathrm{~mm}$ and seven patients $(53.8 \%)$ with a diameter $4.0-6.9 \mathrm{~mm}$ for the

Table 1. Comparison of patient-related and aneurysm-related characteristics of true type and junctional type PCoA aneurysms

\begin{tabular}{|c|c|c|c|}
\hline Characteristic & True PCoA aneurysm $(n=13)$ & Junctional PCoA aneurysm $(n=80)$ & $p$-value \\
\hline Age (years) & $57.31 \pm 12.83$ & $62.54 \pm 13.13$ & $0.205^{\ddagger}$ \\
\hline Gender & & & $0.634^{\dagger}$ \\
\hline Male & $2(15.4)$ & $13(16.3)$ & \\
\hline Female & $11(84.6)$ & $67(83.8)$ & \\
\hline Modified Fisher grade & & & $0.513^{\dagger}$ \\
\hline $1-2$ & $2(15.4)$ & $24(30.0)$ & \\
\hline $3-4$ & $11(84.6)$ & $56(70.0)$ & \\
\hline WFNS grade & & & $0.853^{\dagger}$ \\
\hline $1-3$ & $11(84.6)$ & $67(83.8)$ & \\
\hline $4-5$ & $2(15.4)$ & $13(16.3)$ & \\
\hline Oculomotor nerve palsy & & & $0.250^{\dagger}$ \\
\hline Absent & $13(100.0)$ & $73(91.3)$ & \\
\hline Present & $0(0.0)$ & $7(8.8)$ & \\
\hline Diameter of aneurysm (mm) & $4.45 \pm 1.44$ & $7.68 \pm 3.36$ & $0.001^{*, \neq}$ \\
\hline Aneurysm diameter (mm) & & & $<0.001^{*,+}$ \\
\hline$<4$ & $6(46.2)$ & $2(2.5)$ & \\
\hline $4.0-6.9$ & $7(53.8)$ & $37(46.3)$ & \\
\hline $7.0-9.9$ & $0(0.0)$ & $30(37.5)$ & \\
\hline$\geq 10$ & $0(0.0)$ & $11(13.8)$ & \\
\hline Neck diameter of PCoA aneurysm (mm) & $2.52 \pm 0.76$ & $4.42 \pm 2.11$ & $0.002^{*, \neq}$ \\
\hline Height of PCoA aneurysm (mm) & $4.01 \pm 1.47$ & $6.76 \pm 3.20$ & $0.002^{*, \neq}$ \\
\hline Aspect ratio & $1.70 \pm 0.72$ & $1.67 \pm 0.69$ & $0.891^{\ddagger}$ \\
\hline Diameter of PCoA (mm) & $1.90 \pm 0.57$ & $1.15 \pm 0.49$ & $<0.001^{*, \neq}$ \\
\hline Ipsilateral PCoA/P1 & $2.67 \pm 1.22$ & $1.14 \pm 0.88$ & $<0.001^{*, \neq}$ \\
\hline Treatment & & & $0.562^{\dagger}$ \\
\hline Surgical clipping & $7(53.8)$ & $39(48.8)$ & \\
\hline Endovascular coiling & $6(46.2)$ & $41(51.3)$ & \\
\hline 3-month mRS score & & & $0.457^{\dagger}$ \\
\hline $0-3$ & $10(76.9)$ & $69(86.3)$ & \\
\hline $4-6$ & $3(23.1)$ & 11 (13.8) & \\
\hline
\end{tabular}

Values are presented as mean \pm standard deviation or number (\%). ${ }^{*}$ Denotes statistically significant $p$-value. ${ }^{\dagger}$ Chi-square test. ${ }^{\ddagger}$ Two sample t-test. PCoA : posterior communicating artery, WFNS : World Federation of Neurosurgical Societies, mRS : modified Rankin Scale 
true PCoA aneurysms; two patients $(2.5 \%)$ with a diameter $<4$ $\mathrm{mm}, 37$ patients $(46.3 \%)$ with a diameter $4.0-6.9 \mathrm{~mm}, 30$ patients $(37.5 \%)$ with a diameter $7.0-9.9 \mathrm{~mm}$, and 11 patients $(13.8 \%)$ with a diameter $\geq 10 \mathrm{~mm}$ for the junctional PCoA aneurysms.

The neck diameter of the true PCoA aneurysm was significantly smaller than that of the junctional PCoA aneurysms (mean aneurysm neck diameter \pm SD, $2.52 \pm 0.76$ vs. $4.42 \pm 2.11$ $\mathrm{mm}, p=0.002$ ). The neck diameter of the ruptured true PCoA aneurysms ranged from 1.5 to $3.8 \mathrm{~mm}$, while the neck diameter of the ruptured junctional PCoA aneurysm ranged from 2.1 to $17.3 \mathrm{~mm}$. Furthermore, the height of the true PCoA aneurysms was significantly smaller than that of the junctional $\mathrm{PCoA}$ aneurysms (mean aneurysm height $\pm \mathrm{SD}, 4.01 \pm 1.47$ vs. $6.76 \pm 3.20 \mathrm{~mm} ; p=0.002$ ). The height of the ruptured true PCoA aneurysms ranged from 1.8 to $6.7 \mathrm{~mm}$, while the height of the ruptured junctional PCoA aneurysms ranged from 2.2 to $20.1 \mathrm{~mm}$. Thus, the aspect ratio (the ratio of the aneurysm height to the aneurysm neck diameter) was not significantly different between the two groups (mean aspect ratio of the aneurysm $\pm S D, 1.70 \pm 0.71$ vs. $1.67 \pm 3.20 ; p=0.891$ ). The aspect ratio of the ruptured true $\mathrm{PCOA}$ aneurysms ranged from 0.8 to 2.9, while the aspect ratio of the ruptured junctional PCoA aneurysms ranged from 0.7 to 3.7 .

Meanwhile, the diameter of the PCoA was significantly larger in the true PCoA aneurysm group than that in the group of a junctional PCoA aneurysm (mean PCoA diameter $\pm \mathrm{SD}, 1.90 \pm 0.57$ vs. $1.15 \pm 0.49 \mathrm{~mm} ; p<0.001)$. The PCoA diam- eter in the true PCoA aneurysm group ranged from 1.2 to 2.8 $\mathrm{mm}$, while the PCoA diameter in the junctional PCoA aneurysm group ranged from 0.3 to $2.1 \mathrm{~mm}$. In addition, the ipsilateral $\mathrm{PCoA} / \mathrm{P} 1$ ratio was significantly larger in the true PCoA aneurysm group than that in the group of a junctional PCoA aneurysm (mean PCoA/P1 ratio \pm SD, $2.67 \pm 1.22$ vs. 1.14 $\pm 0.88 ; p<0.001)$.

No between-group difference was identified for the modified Fisher grade, WFNS clinical grade at admission, presentation with the oculomotor nerve palsy, treatment modality (surgical vs. endovascular treatment), and 3-month mRS score. For the true PCoA aneurysm group, the WFNS clinical grade at admission was $1-3$ for 11 patients (84.6\%) and 4 or 5 for two patients (15.4\%), while the modified Fisher grade was 1 or 2 for two patients (15.4\%) and 3 or 4 for 11 patients (84.6\%). No patient presented with oculomotor nerve palsy. Surgical clip placement was used as the treatment modality to obliterate the ruptured aneurysm in seven patients (53.8\%), while endovascular coiling was applied to six patients (46.2\%). The proportion of patients with a favorable outcome (mRS score $0-3$ ) at 3 months after admission was $76.9 \%$ (10 of 13 patients).

\section{Ruptured very small PCoA aneurysms less than $4 \mathrm{~mm}$}

A total of eight patients presented with a ruptured very small aneurysm with a diameter $<4 \mathrm{~mm}$ (Table 2). Fig. 1 illustrates DSA images of six patients with a ruptured, very small true PCoA aneurysm. The incidence of very small aneurysms

Table 2. Clinical and angiographic characteristics of eight patients with a ruptured PCoA aneurysm with a diameter less than $4 \mathrm{~mm}$

\begin{tabular}{|c|c|c|c|c|c|c|c|c|c|c|c|}
\hline $\begin{array}{r}\text { Case } \\
\text { No. }\end{array}$ & $\begin{array}{c}\text { Age } \\
\text { (years)/ } \\
\text { sex }\end{array}$ & $\begin{array}{c}\text { Aneurysm } \\
\text { type }\end{array}$ & $\begin{array}{c}\text { Modified } \\
\text { Fisher } \\
\text { grade }\end{array}$ & $\begin{array}{l}\text { WFNS } \\
\text { grade }\end{array}$ & $\begin{array}{l}\text { Maximum } \\
\text { aneurysm } \\
\text { diameter } \\
(\mathrm{mm})\end{array}$ & $\begin{array}{c}\text { Aspect } \\
\text { ratio }\end{array}$ & $\begin{array}{c}\text { PCoA } \\
\text { diameter } \\
(\mathrm{mm})\end{array}$ & $\begin{array}{l}\text { Ipsilateral } \\
\text { PCoA/P1 }\end{array}$ & Treatment & $\begin{array}{l}\text { Intraoperative } \\
\text { rupture }\end{array}$ & $\begin{array}{l}\text { 3-month } \\
\text { mRS }\end{array}$ \\
\hline 1 & $56 / F$ & True & 4 & 2 & 2.6 & 1.1 & 2.8 & 5.6 & Clipping & + & 1 \\
\hline 2 & $40 / F$ & True & 3 & 1 & 2.7 & 1.1 & 2.1 & 2.1 & Clipping & - & 0 \\
\hline 3 & $56 / F$ & True & 3 & 2 & 2.8 & 1.1 & 2.0 & 2.4 & Clipping & + & 0 \\
\hline 4 & $51 / \mathrm{F}$ & True & 3 & 2 & 3.4 & 2.3 & 1.7 & 1.7 & Clipping & + & 0 \\
\hline 5 & $84 / F$ & True & 3 & 2 & 3.4 & 1.1 & 2.2 & 3.7 & Coiling & NA & 2 \\
\hline 6 & $67 / F$ & True & 3 & 3 & 3.6 & 0.8 & 2.1 & 3.3 & Clipping & - & 0 \\
\hline 7 & $55 / \mathrm{M}$ & Junctional & 3 & 2 & 2.5 & 1.3 & 0.5 & 0.3 & Clipping & - & 0 \\
\hline 8 & $54 / F$ & Junctional & 3 & 4 & 3.9 & 1.9 & 0.3 & 0.3 & Clipping & - & 1 \\
\hline
\end{tabular}

PCoA : posterior communicating artery, WFNS : World Federation of Neurosurgical Societies, mRS : modified Rankin Scale, F : female, NA : not associated, $M$ : male 
was $46.2 \%$ (six of 13 patients) in the ruptured true PCoA aneurysm group and only $2.5 \%$ (two of 80 patients) in the ruptured junctional PCoA aneurysm group.

Among the 13 cases of a ruptured true PCoA aneurysm, six cases $(46.2 \%)$ had a diameter $<4 \mathrm{~mm}$, ranging from 2.6 to 3.6 $\mathrm{mm}$, while the other seven cases (53.8\%) had diameters ranging from 4.8 to $6.7 \mathrm{~mm}$.

All the patients with a very small aneurysm presented with a thick subarachnoid hemorrhage (modified Fisher grade 3 or 4), although only one patient showed a poor WFNS clinical grade (WFNS grade 4 in case 8 ). For the eight patients with a ruptured aneurysm $<4 \mathrm{~mm}$, surgical clip placement was applied to seven patients (five patients with a true PCoA aneurysm and two patients with a junctional PCoA aneurysm), while endovascular coiling was only applied to one patient with a true PCoA aneurysm (case 5). Obliteration of the ruptured aneurysm was successfully achieved in all patients with- out procedure-related complications.

In the intraoperative microscope video recordings, an intraoperative rupture due to the structural fragility of the aneurysm was identified during peri-aneurysmal dissection in three patients (60.0\%, three of five surgical cases) with a very small true PCoA aneurysm, yet did not occur in any of the cases of a very small junctional PCoA aneurysm.

\section{DISCUSSION}

If an aneurysm is found at the junctional area of the ICA and PCoA, careful angiographic evaluation is required to determine the exact origin of the aneurysm, particularly in cases of a large PCoA diameter or large infundibular widening. In this study, true PCoA aneurysms were found to be more prone to rupture at a smaller size than junctional PCoA aneurysms,
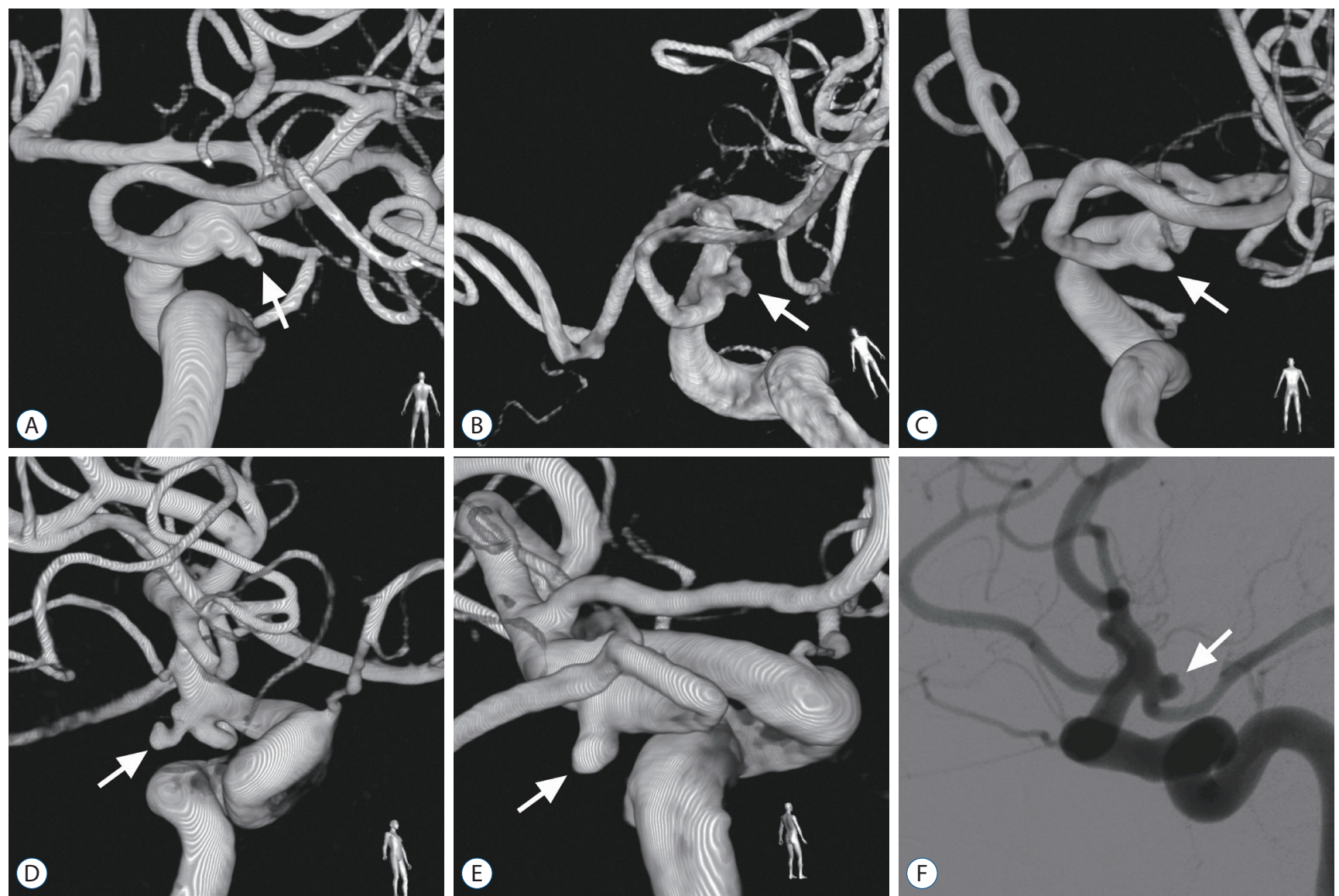

Fig. 1. Digital subtraction angiography for patients with a ruptured true posterior communicating artery aneurysm (arrow) with a diameter $<4 \mathrm{~mm}$. A : Right carotid angiogram in case 1. B : Right carotid angiogram in case 2. C : Right carotid angiogram in case 3. D : Right carotid angiogram in case 4. E : Left carotid angiogram in case 5 . F : Right carotid angiogram in case 6. 
where half of the true PCoA aneurysms ruptured with a diameter less than $4 \mathrm{~mm}$.

True PCoA aneurysms originating from the PCoA itself were considered rare and have been described in case reports ${ }^{4,9,11,17,25,32,33)}$. In a systematic review, the incidence of such aneurysms was revealed as $1.3 \%$ among intracranial aneurysms and $6.8 \%$ among PCoA aneurysms ${ }^{5}$.

However, careful angiographic evaluation in recent clinical studies revealed a higher incidence of true PCoA aneurysms ${ }^{6}$. In most cases, true PCoA aneurysms are located within a few millimeters from the ICA. In particular, it is difficult to discriminate aneurysms arising from the PCoA origin or infundibulum from junctional PCoA aneurysms arising from the ICA. A careful evaluation by He et al. ${ }^{6}$ ) using computed tomography (CT) angiography with volume-rendered reconstructions showed the incidence of true PCoA aneurysms to be as high as $13.0 \%$ among PCoA aneurysms, which is comparable to the present study result of $14.0 \%$ (13 patients of 93 patients) using three-dimensional rotational angiography. Thus, careful evaluation of the neck location and anatomy of the aneurysm is recommended using three-dimensional rotational angiography or CT angiography.

In a morphometric study of a PCoA aneurysm by He et al. ${ }^{6}$ using patient data from a single hospital, 10 true PCoA aneurysms and 67 junctional PCoA aneurysms were analyzed and compared. Although the prevalence of ruptured aneurysms was similar in both groups as about $80 \%$, the aneurysm size was statistically smaller for the true PCoA aneurysms (0.072 \pm 0.04 vs. $0.14 \pm 0.1 \mathrm{~cm}^{3}, p=0.03$ ). They suggested that true PCoA aneurysms might be more prone to rupture than junctional PCoA aneurysms. Similarly, the present study found that true PCoA aneurysms ruptured at a smaller size than the junctional PCoA aneurysms. In particular, a high rupture risk of very small true PCoA aneurysms $<4 \mathrm{~mm}$ was highlighted, as $46.2 \%$ cases of the true PCoA aneurysms ruptured with a diameter $<4 \mathrm{~mm}$, whereas only $2.5 \%$ cases of the junctional PCoA aneurysms ruptured with a diameter $<4 \mathrm{~mm}$.

Given the acute angles required for the microcatheter to navigate from the ICA to the PCoA, and then into the aneurysm within a very short distance, microsurgical clipping was favored over endovascular coiling for the present series of a ruptured true PCoA aneurysm $<4 \mathrm{~mm}$. In the surgical series, intraoperative rupture during peri-aneurysmal dissection occurred in $60 \%$ of the very small true PCoA aneurysms $<4$ $\mathrm{mm}$. The structural fragility of such aneurysms and their potential location in an intra-operative blind spot necessitate appropriate surgical strategies and tactics ${ }^{12}$. First, the application of temporary clips on both the proximal and distal arteries is crucial to provide a clean surgical field in cases of an intraoperative rupture. Careful dissection and adequate preparation of a fragile aneurysm in a clean surgical field is essential for safe permanent clipping. Second, a true PCoA aneurysm arising distal to the origin of the PCoA can lie in the intra-operative blind spot. An angled endoscope or micro-mirror can be used to look behind the ICA blocking the view of the microscope. In particular, a micro-mirror can show indocyanine green angiographic imaging to verify the presence of any residual aneurysm or the occlusion of the associated thalamoperforating arteries developed by the clip ${ }^{13)}$.

The natural course and rupture risk of an unruptured aneurysm vary according to its size, shape, and location. First, many studies have already evaluated the rupture risk of unruptured aneurysms based on the maximum diameter of the aneurysm. In the first phase of the International Study of Unruptured Intracranial Aneurysms (ISUIA) including retrospective natural history data, aneurysms with a diameter $\geq 10$ $\mathrm{mm}$ were associated with a significantly increased risk of rupture $^{8)}$. In the second phase of ISUIA including a prospective natural history study and the Unruptured Cerebral Aneurysm Study Japan study, a new cut-off diameter $>7 \mathrm{~mm}$ was associated with a higher risk of aneurysm rupture ${ }^{28,31)}$. Moreover, a meta-analysis conducted by Wermer et al. ${ }^{30)}$ revealed an aneurysm diameter $>5 \mathrm{~mm}$ as a significant risk factor of rupture, while the Small Unruptured Aneurysm Verification study presented the smallest diameter of $4 \mathrm{~mm}$ as the risk cut-off for aneurysm rupture ${ }^{22}$. As a result, these clinical studies have been used to determine guidelines for the management of patients with unruptured intracranial aneurysms $\mathrm{s}^{10,23,277}$.

Thus, when considering that a $4 \mathrm{~mm}$ diameter is the smallest recognized risk cut-off for aneurysm rupture, the fact that half of the ruptured true PCoA aneurysm in the present study were very small aneurysms with a diameter $<4 \mathrm{~mm}$ is clinically important for the neurovascular surgeons deciding the treatment of unruptured aneurysms. In particular, previous studies based on pre- and postrupture imaging of ruptured aneurysms showed an increase in aneurysm size and new lobulations after rupture in most cases ${ }^{20,21}$. Thus, appropriate treatment should be considered for unruptured true PCoA 
aneurysm with a diameter $<4 \mathrm{~mm}$, as this study found the diameter of ruptured true PCoA aneurysms to range from 2.6 to $3.6 \mathrm{~mm}$ in six of 13 cases $(46.2 \%)$.

Second, the aneurysm shape characteristics associated with a risk of rupture and requiring surgical or endovascular treatment include a daughter sac, irregular shape, narrow neck, and high aspect ratio ${ }^{1-3,16,19,24,29)}$. Even very small aneurysms need to be treated in the case of morphological characteristics that suggest structural fragility. Thus, a very small true PCoA aneurysm with morphological characteristics associated with a risk of rupture should be considered for treatment.

Third, certain locations of intracranial aneurysms are known to be rupture risk associated in literature, including an anterior communicating artery, internal carotid-PCoA, and posterior circulation $^{7,28,30)}$. Moreover, the present study suggests that an aneurysm location on the PCoA itself also presents a risk of rupture.

Fourth, patient factors reported to be associated with aneurysm rupture include uncontrolled hypertension, current smoking, history of subarachnoid hemorrhage, and female $\operatorname{sex}^{7,15,30)}$.

In a morphometric study of PCoA aneurysms by He et al. ${ }^{6}$ using CT angiography, the PCoA diameter was reported to be significantly larger in the true PCoA aneurysm group (mean PCoA diameter $\pm S D, 2.12 \pm 0.34$ vs. $1.37 \pm 0.41 \mathrm{~mm} ; p<0.001)$. This result also corresponds with the results of the present study using three-dimensional rotational angiography, where the PCoA diameter was significantly larger in the patients with a true PCoA aneurysm (mean PCoA diameter \pm SD, 1.90 \pm 0.57 vs. $1.15 \pm 0.49 \mathrm{~mm} ; p<0.001)$.

An outcome study after a subarachnoid hemorrhage by Taylor et al. ${ }^{26)}$ showed that aneurysms with a diameter $\leq 5$ $\mathrm{mm}$ produced a thicker subarachnoid hemorrhage (Fisher grade 3 or 4) than larger aneurysms without a between-group difference in the clinical outcome. Similarly, all patients with a ruptured PCoA aneurysm $<4 \mathrm{~mm}$ in the present study developed a thick subarachnoid hemorrhage with Fisher grade 3 or 4 , and the clinical outcome were favorable for all patients with a $\mathrm{mRS}$ score of $0-2$ at 3 months.

This study is limited because it is a retrospective review of a relatively small case series from a single institution. Despite the low prevalence of true PCoA aneurysms, careful angiographic evaluation using 3D rotational angiography revealed the inclusion of 13 patients with a true PCoA aneurysm in this study. In addition, all the surgical procedures were performed at a single institution, potentially limiting the generalizability of the surgical outcomes. However, the surgical techniques for a ruptured ICA aneurysm are already standardized at university hospitals.

\section{CONCLUSION}

The current data based on 3D rotational DSA revealed a $14 \%$ incidence of true PCoA aneurysms among a group of ruptured aneurysms at the junctional area of the ICA and PCoA. True PCoA aneurysms were found to be associated with a larger PCoA, and ruptured at a smaller maximum diameter than junctional PCoA aneurysms. In particular, the ruptured aneurysm with a very small diameter $<4 \mathrm{~mm}$ was observed with an incidence of $46.2 \%$ in the ruptured true PCoA aneurysm group, yet only $2.5 \%$ in the junctional PCoA aneurysm group. In addition, the neck diameter and height of the true PCoA aneurysms were also significantly smaller than the junctional PCoA aneurysms.

\section{CONFLICTS OF INTEREST}

Jaechan Park has been editorial board of JKNS since November 2014. He was not involved in the review process of this original article. No other potential conflict of interest relevant to this article was reported.

\section{INFORMED CONSENT}

This type of study does not require informed consent.

\section{AUTHOR CONTRIBUTIONS}

\author{
Conceptualization : JP \\ Data curation : BJK, DGS, MK \\ Formal analysis : $\mathrm{BJK}, \mathrm{MK}$ \\ Funding acquisition : JP \\ Methodology : BJK, IHS, MK \\ Project administration : BJK, MK \\ Visualization : BJK, MK
}




\author{
Writing - original draft : DGS \\ Writing - review \& editing : JP
}

\section{ORCID}

$\begin{array}{ll}\text { Dong Gyu Shin } & \text { https://orcid.org/0000-0002-6387-7518 } \\ \text { Jaechan Park } & \text { https://orcid.org/0000-0001-7572-3260 } \\ \text { Myungsoo Kim } & \text { https://orcid.org/0000-0003-2764-2508 } \\ \text { Byoung-Joon Kim } & \text { https://orcid.org/0000-0002-9375-1799 } \\ \text { Im Hee Shin } & \text { https://orcid.org/0000-0002-9136-2407 }\end{array}$

\section{- Acknowledgements}

This research was supported by a grant from the Korea Health Technology R\&D Project through the Korea Health Industry Development Institute (KHIDI), funded by the Ministry of Health \& Welfare, Republic of Korea (HI15C0001).

\section{References}

1. Backes $D$, Vergouwen MD, Velthuis BK, van der Schaaf IC, Bor AS, Algra $A$, et al. : Difference in aneurysm characteristics between ruptured and unruptured aneurysms in patients with multiple intracranial aneurysms. Stroke 45 : 1299-1303, 2014

2. Björkman J, Frösen J, Tähtinen O, Backes D, Huttunen T, Harju J, et al. : Irregular shape identifies ruptured intracranial aneurysm in subarachnoid hemorrhage patients with multiple aneurysms. Stroke 48 : 1986-1989, 2017

3. Fung C, Mavrakis E, Filis A, Fischer I, Suresh M, Tortora A, et al. : Anatomical evaluation of intracranial aneurysm rupture risk in patients with multiple aneurysms. Neurosurg Rev 42 : 539-547, 2019

4. Guo J, Chen Q, Miao H, Feng H, Zhu G, Chen Z : True posterior communicating artery aneurysms with or without increased flow dynamical stress: report of three cases. Clin Neurol Neurosurg 116 : 93-95, 2014

5. He W, Gandhi CD, Quinn J, Karimi R, Prestigiacomo CJ : True aneurysms of the posterior communicating artery: a systematic review and metaanalysis of individual patient data. World Neurosurg 75 : 64-72; discussion 49, 2011

6. He W, Hauptman J, Pasupuleti L, Setton A, Farrow MG, Kasper L, et al. : True posterior communicating artery aneurysms: are they more prone to rupture? A biomorphometric analysis. J Neurosurg $112: 611-615$, 2010

7. Ikawa F, Morita A, Tominari S, Nakayama T, Shiokawa Y, Date I, et al. : Rupture risk of small unruptured cerebral aneurysms. J Neurosurg 25 : 1-10, 2019
8. International Study of Unruptured Intracranial Aneurysms Investigators : Unruptured intracranial aneurysms--risk of rupture and risks of surgical intervention. N Engl J Med 339 : 1725-1733, 1998

9. Kaspera W, Majchrzak H, Kopera M, Ładziński P : "True" aneurysm of the posterior communicating artery as a possible effect of collateral circulation in a patient with occlusion of the internal carotid artery. A case study and literature review. Minim Invasive Neurosurg 45 : 240 244, 2002

10. Komotar RJ, Mocco J, Solomon RA : Guidelines for the surgical treatment of unruptured intracranial aneurysms: the first annual J. Lawrence pool memorial research symposium--controversies in the management of cerebral aneurysms. Neurosurgery 62 : 183-193; discussion 193194, 2008

11. Kudo $T$ : An operative complication in a patient with a true posterior communicating artery aneurysm: case report and review of the literature. Neurosurgery $27:$ 650-653, 1990

12. Kuzmik GA, Bulsara KR : Microsurgical clipping of true posterior communicating artery aneurysms. Acta Neurochir (Wien) 154 : 17071710,2012

13. Lee Y, Kim M, Park J, Kim BJ, Son W, Jung S : Mirroring with indocyanine green angiography in aneurysm surgery: technical note and case presentations. World Neurosurg 132 : e696-e703, 2019

14. Molyneux A, Kerr R, Stratton I, Sandercock P, Clarke M, Shrimpton J, et al. : International Subarachnoid Aneurysm Trial (ISAT) of neurosurgical clipping versus endovascular coiling in 2143 patients with ruptured intracranial aneurysms: a randomised trial. Lancet 360 : 1267-1274, 2002

15. Müller TB, Vik A, Romundstad PR, Sandvei MS : Risk factors for unruptured intracranial aneurysms and subarachnoid hemorrhage in a prospective population-based study. Stroke $50: 2952-2955,2019$

16. Nader-Sepahi A, Casimiro M, Sen J, Kitchen ND : Is aspect ratio a reliable predictor of intracranial aneurysm rupture? Neurosurgery 54 : 1343-1347; discussion 1347-1348, 2004

17. Nakano Y, Saito T, Yamamoto J, Takahashi M, Akiba D, Kitagawa T, et al. : Surgical treatment for a ruptured true posterior communicating artery aneurysm arising on the fetal-type posterior communicating artery-two case reports and review of the literature. J UOEH $33: 303-312$, 2011

18. Park J, Woo H, Kang DH, Kim YS, Kim MY, Shin IH, et al. : Formal protocol for emergency treatment of ruptured intracranial aneurysms to reduce in-hospital rebleeding and improve clinical outcomes. J Neurosurg $122:$ 383-391, 2015

19. Pierot L, Barbe C, Ferré JC, Cognard C, Soize S, White P, et al. : Patient and aneurysm factors associated with aneurysm rupture in the population of the ARETA study. J Neuroradiol 47 : 292-300, 2020

20. Rahman M, Ogilvy CS, Zipfel GJ, Derdeyn CP, Siddiqui AH, Bulsara KR, et al. : Unruptured cerebral aneurysms do not shrink when they rupture: multicenter collaborative aneurysm study group. Neurosurgery 68 : 155-160; discussion 160-161, 2011

21. Schneiders JJ, Marquering HA, van den Berg R, VanBavel E, Velthuis B, Rinkel $G J$, et al. : Rupture-associated changes of cerebral aneurysm ge- 
ometry: high-resolution 3D imaging before and after rupture. AJNR Am

J Neuroradiol 35 : 1358-1362, 2014

22. Sonobe M, Yamazaki T, Yonekura M, Kikuchi H : Small unruptured intracranial aneurysm verification study: SUAVe study, Japan. Stroke 41 : 1969-1977, 2010

23. Steiner $T$, Juvela $S$, Unterberg $A$, Jung $C$, Forsting $M$, Rinkel $G$, et al. : European Stroke Organization guidelines for the management of intracranial aneurysms and subarachnoid haemorrhage. Cerebrovasc Dis $35: 93-112,2013$

24. Suzuki T, Takao H, Rapaka S, Fujimura S, Ioan Nita C, Uchiyama Y, et al. : Rupture risk of small unruptured intracranial aneurysms in Japanese adults. Stroke $51: 641-643,2020$

25. Takeda M, Kashimura H, Chida K, Murakami T : Microsurgical clipping for the true posterior communicating artery aneurysm in the distal portion of the posterior communicating artery. Surg Neurol Int 6 : 101, 2015

26. Taylor CL, Steele D, Kopitnik TA Jr, Samson DS, Purdy PD : Outcome after subarachnoid hemorrhage from a very small aneurysm: a case-control series. J Neurosurg 100 : 623-625, 2004

27. Thompson BG, Brown RD Jr, Amin-Hanjani S, Broderick JP, Cockroft KM, Connolly ES Jr, et al. : Guidelines for the management of patients with unruptured intracranial aneurysms: a guideline for healthcare profes- sionals from the American Heart Association/American Stroke Association. Stroke $46:$ 2368-2400, 2015

28. UCAS Japan Investigators, Morita A, Kirino T, Hashi K, Aoki N, Fukuhara $S$, et al. : The natural course of unruptured cerebral aneurysms in a Japanese cohort. N Engl J Med 366 : 2474-2482, 2012

29. Ujiie H, Tamano $Y$, Sasaki $K$, Hori $T$ : Is the aspect ratio a reliable index for predicting the rupture of a saccular aneurysm? Neurosurgery 48 : 495-502; discussion 502-503, 2001

30. Wermer MJ, van der Schaaf IC, Algra A, Rinkel GJ : Risk of rupture of unruptured intracranial aneurysms in relation to patient and aneurysm characteristics: an updated meta-analysis. Stroke 38 : 1404-1410, 2007

31. Wiebers DO, Whisnant JP, Huston J 3rd, Meissner I, Brown RD Jr, Piepgras DG, et al. : Unruptured intracranial aneurysms: natural history, clinical outcome, and risks of surgical and endovascular treatment. Lancet 362 : 103-110, 2003

32. Yang ZG, Liu J, Ge J, Li ZF, Tian CO, Han J, et al. : A novel proximal end stenting technique for assisting embolization of a complex true posterior communicating aneurysm. J Clin Neurosci 28 : 148-151, 2016

33. Yoshida M, Watanabe M, Kuramoto S: "True" posterior communicating artery aneurysm. Surg Neurol 11 : 379-381, 1979 